\title{
Antibacterial Activity of Polygonum plebejum and Euphorbia hirta Against Staphylococcus aureus (MRSA)
}

\author{
Eman S. Abdelkhalek ${ }^{1 *}$, Atef A. El-Hela², Aziza Hamed El-Kasaby ${ }^{1}$, Nagwa M. \\ Sidkey ${ }^{1}$, Enayat M. Desouky ${ }^{1}$ and Heba H. Abdelhaleem ${ }^{3}$ \\ ${ }^{1}$ Botany and Microbiology Department, Faculty of Science (Girls), Al-Azhar University, Cairo, Egypt. \\ ${ }^{2}$ Pharmaceutical Department, Faculty of Pharmacy (Boys), Al-Azhar University Cairo, Egypt. ${ }^{3}$ Inspector of \\ Occupational Safety and Health at the Ministry of Manpower.
}

\begin{abstract}
The agar diffusion method was used to determine the antimicrobial activities of Euphorbia hirta (EH) and Polygonum plebeium (PP) against S.aureus, B39. Ethyl acetate extract of Euphorbia hirta (EH) and Polygonum plebejum (PP), was the most effective solvent. MIC of plant extract Polygonum plebeium (PP) and Euphorbia hirta (EH) was $25 \mathrm{mg} / \mathrm{ml}$. The antimicrobial activity of ethyl acetate extract of $E$. hirta (EH) and $P$. plebeium (PP) was more effective when incubated at $25^{\circ} \mathrm{C}$ for 10 min with MRSA, B39; pH 5 was more effective against MRSA, B39. Light condition for $24 \mathrm{hr}$ was effective against MRSA, B39; Static condition had slight effectiveness against MRSA, B39. Xylose exhibited the highest activity on MRSA, B39; no amino acids, metallic ions and vitamins were effective. Ethyl acetate extract of $E$. hirta (EH) was subjected to column chromatography and monitored with TLC, 5 spots were detected. Anti MRSA spots were identified as Hydroquinone and O-coumaric acid.
\end{abstract}

Keywords: MRSA; Euphorbia hirta; Polygonum Plebeium; medicinal plants; resistant bacteria.

\footnotetext{
*Correspondence: emanshawky_emanshawky@yahoo.com

(Received: 29 September 2018; accepted: 08 November 2018)
}

Citation: Eman S. Abdelkhalek, Atef A. El-Hela, Aziza Hamed El-Kasaby, Nagwa M.Sidkey, Enayat M. Desouky and Heba H. Abdelhaleem, Antibacterial activity of Polygonum plebejum and Euphorbia hirta against Staphylococcus aureus (MRSA), J Pure Appl Microbiol., 2018; 12(4):2205-2216. http://dx.doi.org/10.22207/JPAM.12.4.60

(c) The Author(s) 2018. Open Access. This article is distributed under the terms of the Creative Commons Attribution 4.0 International License which permits unrestricted use, sharing, distribution, and reproduction in any medium, provided you give appropriate credit to the original author(s) and the source, provide a link to the Creative Commons license, and indicate if changes were made. 


\section{INTRODUCTION}

Since the discovery of the first antibiotic, penicillin, the employment of any novel antibiotic has been followed by the appearance of bacterial resistance to that antibiotic in as little time as a few years. Antibiotics have the ability to kill bacteria or inhibit their growth. Resistance to antibiotics is one of the biggest problems that global public health is facing [1]. Antimicrobial resistance is not new, but the number of resistant organisms, the geographic locations affected by drug resistance, and the breadth of resistance in single organisms are unprecedented and mounting [2]. Diseases and disease agents that were once thought to be controlled by antibiotics are returning in new leagues resistant to these therapies. In this review, we focus on the underlying principles and ecological factors that affect drug resistance in bacteria. It should be stressed, however, that antimicrobial resistance is also evident in other microorganisms-namely, parasites, fungi and viruses [3]. Drug-resistant strains initially appeared in hospitals, where most antibiotics were being used [2]. Penicillin resistant Staphylococcus aureus confronted London civilian hospitals very soon after the introduction of penicillin in the 1940s [4]. Similarly, Resistance to multiple drugs was first detected among enteric bacteria-namely, Escherichia coli, Shigella and Salmonella-in the late 1950s to early 1960s [5], [6]. Such strains posed severe clinical problems and cost lives, particularly in developing countries. Nevertheless, the resistance problem was perceived by some, most notably those in the industrialized world, as a curiosity of little health concern confined to gastrointestinal organisms in distant countries. This attitude changed in the 1970s when Haemophilus influenzae and Neisseria gonorrhoeae, organisms that cause respiratory and genitourinary disease, respectively, emerged with resistance to ampicillin [7], [8]. Resistant infections affect treatment costs, disease spread and duration of illness [9]. In order to find novel antimicrobial agents with new modes of action, plants have been explored as sources for the identification of new and effective antibacterials. An endless number of plant species have been reported to act against several bacteria in vitro, and many medicinal plants produce secondary metabolites (phytochemicals) capable of inhibiting the growth of a wide range of microorganisms including fungi, yeasts and bacteria. Phytochemicals have been studied for the treatment of microbial infections since 1990, due to the increasing inefficacy of conventional antibiotics with potential therapeutic effects [10],[11]. Since the synthetic drugs are more costly and lead to side effects, the usage of herbal medicines are getting importance due to promising results and less or no side effects. The plant containing active biological compounds are prepared from various parts of medicinal plants. [12] reported that, medicinal plants have great potential as antimicrobial agents against MDR clinical isolates. Polygonum plebejum, occurs in disturbed habitats that frequently are flooded, such as banks, ditches, and rice fields. It is used as a vegetable in food in some locations [13].

\section{MATERIALS AND METHODS Media Used}

Nutrient Agar Medium (NAM) (Hi Media, India). It was prepared as manufactures direction.

\section{Types of medicinal plants used}

Nine types of medicinal plants were collected from different locations as following: Euphorbia hirta (EH), Lolium temulentum (LT), Minuartia cumberlandensis (MC) ,Polygonum plebeium (PP), Silene rubella (SR) Gemellina hystrix $(\mathrm{GH})$ were collected from Tanta region. While Thymus decussatus (TD) collected from Sant Catren, Kalanchoe marmorata (KM) collected from Orman garden and Forsskaolea tenacissima (FT) collected from garden of Al-Azhar university then were kept in the freezing conditions during the experimental studies.

\section{Test organisms used}

MRSA, B39 isolated from wound infection in Kobry El-Koba Hospital, Cairo, Egypt.

\section{Preparation and Extraction of plant material}

Ethanolic extraction of plants material was carried out according to the method described by [14] with some modifications.

The leaves of E.hirta and P.plebeium were washed after collection and later grinding until it become powder. 100gm of each plants were soaked in $1200 \mathrm{ml}$ of $70 \%$ ethanol (to precipitate the chlorophylls and resin) for $24 \mathrm{~h}$. Then, the mixture was filtered through double layer of muslin cloth. Repeat these steps 3 times 
until complete extraction occur. The filtrate was concentrate by using rotary evaporator .Then 5 gm of supernatant E.hirta (EH), P. plebeium (PP) mixed with $50 \mathrm{gm}$ of distilled water and equivalent amount of $n$ - hexane (defatting agent \& separation of less polar substances) was mixed together in separating funnel and left it until it stile. Hexane extract of each plant was dried under vacuum using (Rotary evaporator), and kept at $-20^{\circ} \mathrm{C}$ for later use.

The same protocol was used by other solvents (ethyl acetate separation of middle polar substances) \& (n-butanol separation of high polar substances). The synergistic effect of fractions of $P$. plebeium, PP and E.hirta, $\mathrm{EH}$ were tested against MRSA.

Antimicrobial activity of selected medicinal plants against MRSA

The antimicrobial assay was preformed using agar well diffusion method for ethanolic extract of 9 medicinal plants. Only $10 \mu$ of each target resistant strains were inoculated into $100 \mathrm{ml}$ warm nutrient agar medium $\left(45^{\circ} \mathrm{C}\right)$. The media were poured in sterile plates and left for solidification. Each plate is called a seeded plate. The seeded plates with target organisms were cut by sterile cork borer to make holes (11 $\mathrm{mm}$ in diameter). Only $100 \mu \mathrm{l}$ of the plant extracts was transferred into each hole under aseptic conditions. Then, the plates were kept in refrigerator for 2 hours before incubation to permit diffusion of the metabolites before the growth of the resistant pathogenic bacterial strains takes place.

Subsequently, the plates were incubated at $37^{\circ} \mathrm{C}$ for 24 hours and then examined for antimicrobial activities. Duplicate plates were used for each test microorganism Triplicates of measurements were carried out and the mean of inhibition zone diameter was calculated.

Determination of the MIC of E.hirta and $P$.plebeium extracts against selected strains

The minimum inhibitory concentration (MIC) had been determined by agar diffusion method.

Different concentrations of plant extracts were prepared by using distilled water. The different concentrations used were 100, 50, 25, 12.5 and $6.2(\mathrm{mg} / \mathrm{ml})$. Then, $100 \mu$ of different concentrations was placed in the holes. The experiment was carried out in duplicate. The plates were incubated at $37^{\circ} \mathrm{C}$ for $24 \mathrm{hr}$. The response was observed as a clear zone $(\mathrm{mm})$ around the holes. Parameters controlling the growth of the selected strain in relation to mixture of ethyl acetate extract of E.hirta, EH and P. plebeium, PP

The following parameters were carried out to optimize the antimicrobial activity against the resistant pathogenic bacterium strain. Agar diffusion method was used in this respect. After determining each parameter, the best result was applied in the subsequent parameters. Triplicates were used for each particular parameter .The antimicrobial activity was assayed.

Thermal stability

In this respect, ethyl acetate extracts of the extracts $E$. hirta, $\mathrm{EH}$ and $P$. plebeium, PP was incubated at different temperatures $(10.0,25.0$, $35.0,45.0,100$ and $121^{\circ} \mathrm{C}$ ) for several incubation periods $(0,10,1,6,24,48 \mathrm{~h})$ and then used against MRSA.

\section{Different pH's}

The $\mathrm{pH}$ of plant extracts was measured (pH 5.8) and registered. Then the plant extract was modified to different $\mathrm{pH}^{\prime} \mathrm{s}(2.0,3.0,5.0,8.0$ and 9.1) and incubated at $37^{\circ} \mathrm{C}$ for several incubation periods (zero, 10min, 6, 24 and $48 \mathrm{~h}$ ) and then used against the selected resistant pathogenic strains, in order to determine the best $\mathrm{pH}$ and incubation time.

\section{Dark and light}

In this experiment, the plant extracts of E.hirta, EH and P. plebeium, PP was subjected to light and dark for $24 \mathrm{hr}$. and then was used against MRSA in order to examine the effect of dark and light on the antimicrobial activity of plant extracts.

\section{Static and shaken conditions}

Plant extracts E. hirta, EH and P. plebeium, PP was used under static and shaken conditions (50 and $150 \mathrm{rpm}$ ) condition against MRSA.

\section{Different carbon sources}

Different carbon sources (xylose, glucose, fructose, lactose, maltose, carboxy methyl cellulose (CMC), galactose, sucrose and starch) were added at $1 \%$ to the ethyl acetate extracts E.hirta, EH and P. plebeium, PP and then the plant extract was used against the resistant pathogenic strains, in order to determine the best carbon source in combination with the plant extract can affect the resistant pathogenic strain effectively. 


\section{Different amino acids}

Different amino acids were used viz. (DLTryptophan, L-Lysine, L-Arginine, DL- Asparagine , L-Serine, L-Cysteine, L-Alanine, L- Histidine, L-Leucine, L-Phenyl alanine, DL- Threonine and Glycine). Then the previous amino acids were added separately to ethyl acetate extracts of E. hirta, EH and P.plebeium, PP and then used against the resistant pathogenic strain, in order to determine the best amino acid which can increase the efficiency of the antimicrobial activity of the plant extracts.

\section{Different metallic ions}

Different metallic ions were used viz. $\left(\mathrm{ZnSO}_{4}, \mathrm{CaCl}_{2}, \mathrm{MgSO}_{4}, \mathrm{CoCl}_{2}, \mathrm{KCl}\right.$ and EDTA) in three different concentrations 50,100 and 200 (ppm) were added to the ethyl acetate extracts of $E$. hirta, $\mathrm{EH}$ and $P$. plebeium, PP and then the extracts was used against the resistant pathogenic strain, in order to determine the best metallic ion by which the extracts can affect the resistant pathogenic microorganism effectively.

\section{Different vitamins}

In this respect, different types of vitamins were used including nicotinic acid, riboflavin, ascorbic acid and inositol in three different concentrations (50, 100 and 200 ppm) were added to the plant ethyl acetate extracts of $E$. hirta, $\mathrm{EH}$ and $P$. plebeium, PP and then the extracts was used against the resistant pathogenic strain.

Different concentrations of multivitamins capsule Different concentrations (50, 100 and 200 ppm) of centrum capsule were added to the ethyl acetate extract of E. hirta, EH and P. plebeium, PP and then the extracts was used against the resistant pathogenic strain.

Separation and purification of the antimicrobial substance from E. hirta, EH, P.plebeium, PP Materials for chromatography:

1- Silica gel G60 for thin chromatography ( TLC) ( E.Merck ).

2- Silica gel G for column chromatography ( CC) ( E.Merck ).

3- Sephadex LH-20 for CC ( Sigma ).

4- Pre-coated silica TLC plates 60 F 254 ( $20 \times 20$ $\mathrm{cm}$ ) ( E.Merck ).

5- Anhydrous sodium sulphate (Sigma).

Column chromatography

A glass column of $(2.5 \times 50) \mathrm{cm}$ diameter was used for such purpose as shown in plate (22).
The column was packed with activated silica gel as follows: The silica gel was mixed with chloroform as an eluting solvent. A glass rod was often used to stir the slurry to prevent air bubbles from being trapped with the slurry. Once the slurry get homogenous, it was poured cautiously into the empty .column and the column was left overnight until the silica gel was completely settled. The silica gel was occupied $30 \mathrm{~cm}$ of the column. One $\mathrm{ml}$ of crud viscose brown syrup extract was added onto top of the silica.

The elution gradient of different solvent mixtures (20 ml each) was added as follows:

1) Chloroform: ethyl acetate (95:5)

2) Chloroform: ethyl acetate (90: 10)

3) Chloroform: ethyl acetate (85: 15)

4) Chloroform: ethyl acetate (80: 20)

5) Chloroform: ethyl acetate (75:25)

80,85 fractions were collected from E.hirta, EH and P.plebeium, PP respectively each of $10 \mathrm{ml}$. All fractions were tested for their activity using Agar diffusion method against resistant pathogenic strains. The separated fractions were examined by TLC assay for their purity.

Thin layer chromatography (TLC)

\section{Preparation of plates}

Thin Layer Chromatography (TLC) plates were prepared by mixing silica gel $G$ with water at a ratio of (I: $2 \mathrm{w} / \mathrm{v}$ ) in a flask to form slurry then spread evenly over the whole surface of a glass plate $(20 \times 20 \mathrm{~cm})$. The plates were then subjected to air and heat to remove any traces of water. The dry plates were then activated at $80-130^{\circ} \mathrm{C}$ for 2hrs.[15]

Characterization of the most active pure compounds

The following spectroscopic techniques have been used in this experimental work to predict the empirical chemical structure and the suggested molecular formula as well as nomenclature of the most active compound. UV

(UV spectrophotometer Unicom SP 1750 PYE.) using shift reagents to investigate the substitution patterns of the flavonoids. Cochromatography with standards was also performed where possible. Flavonoid and phenolic acids standards available for comparison during the study were rutin, kaempferol, quercetin and myricetin, rutin and hydroqunion, O-coumaic 
acid, ferulic, caffeic and gallic acids (all obtained commercially, from Fluka, Germany).

\section{Mass (MS) spectrum}

Mass spectrum was carried out on Direct part DI-50 to mass analyzer in Shimadzu GC/MSQP5050 (Germany) at the Regional Center for Mycology and Biotechnology (RCMB), Al-Azhar University, Cairo, Egypt. The mass spectroscopy system was used to confirm the purity of the compounds.

\section{Infra red (IR) spectrum}

The Infra-Red absorption spectrum was obtained in the solid state in the form of $\mathrm{KBr}$ discs and recorded using FTIR Shimadzu spectrophotometer (4000-400 cm) (Germany), Chemistry Department, Faculty of Pharmacy, AlAzhar University, Cairo, Egypt.

\section{RESULTS AND DISCUSSION}

Infectious diseases are major causes of morbidity and mortality in the developing world and accounts for about $50 \%$ of all deaths. Some 5.8 million deaths each year in infants and children below 5 years are caused by enteric diseases world wide [16]. Presence of bacteria was different from ward to ward and hospital to hospital based on activities of each hospital.

Identification of bacterial isolate

Bacterial isolate B39 was identified 16s ribosomal RNA in Sigma lab as following:

Antimicrobial activity of $\mathbf{9}$ medicinal plants against MRSA

The production of herbal drug preparations (i.e. extracts), using a variety of methods from simple traditional technologies to advanced extraction techniques is the first step in the value addition of medicinal and aromatic plants bioresources [17].

In the present study from table (1) it was found that, plant extract $P$. plebeium, $\mathrm{PP}$ at concentration $100 \mathrm{mg} / \mathrm{ml}$, and E.hirta were the most medicinal plants effective against MRSA, B39, which inhibited the growth of MRSA by 23.33, $21.0 \mathrm{~mm}$. respectively. While, Minuratia cumberlandensis, MC and Lolium temulentum, LT no effected at any concentration on MRSA, B39.

Table 1. Effect of nine different plant extracts on MRSA, B39

\begin{tabular}{lccccccccc}
\hline Plant extracts & \multicolumn{10}{c}{ Concentrations } \\
\cline { 2 - 11 } & \multicolumn{3}{c}{$100 \mathrm{mg} / \mathrm{ml}$} & \multicolumn{3}{c}{$50 \mathrm{mg} / \mathrm{ml}$} & & $25 \mathrm{mg} / \mathrm{ml}$ \\
\hline Forsskaolea tenacissima & 18.3 & \pm & 0.58 & - & \pm & - & - & \pm & - \\
Minuartia cumberlandensis & - & \pm & - & - & \pm & - & - & \pm & - \\
Euphorbia hirta & 21 & \pm & 0 & 20 & \pm & 0 & 17 & \pm & 1 \\
Gemellma hystrix & 18.7 & \pm & 0.58 & 18 & \pm & 0 & 17 & \pm & 0 \\
Polygonum plebeium & 23.3 & \pm & 0.58 & 20.3 & \pm & 0.58 & 19.3 & \pm & 0.354 \\
Kalanchoe marmorata & 20.3 & \pm & 0.58 & 19 & \pm & 0 & 18.3 & \pm & 1.155 \\
Silene rubella & 19.3 & \pm & 1.15 & 20 & \pm & 0 & 18.7 & \pm & 0.577 \\
Thymus decussatus & 16.7 & \pm & 0.58 & - & \pm & - & - & \pm & - \\
Lolium temulentum & - & \pm & - & - & \pm & - & - & \pm & - \\
\hline
\end{tabular}

These results were in accordance with [18] who showed that, the antimicrobial activity of extract of leaves of E.hirta was effective against Salmonella with diameter of inhibition zone 18 $\mathrm{mm}$.

Determination of MIC of P. plebejum, PP and $E$. hirta $\mathrm{EH}$ against the growth of MRSA

Data illustrated in table $(2 \mathrm{a}, \mathrm{b})$ declared that, the minimum inhibitory concentration (MIC) of plant extract $P$. plebeium , PP and E. hirta, $\mathrm{EH}$ against the growth of MRSA, B39, and was
$25 \mathrm{mg} / \mathrm{ml}$. These results were in contrast with [18] who indicated that, the minimum inhibitory concentration (MIC) of leaf extract E.hirta, EH against the growth of $S$. aureus with value of $12.50 \mathrm{mg} / \mathrm{ml}$.

Extraction of antimicrobial substance from $P$ plebejum, PP , E. hirta, EH , plant extracts by different solvent systems

It was indicated from table (3) that, among all the tested solvent systems ( $\mathrm{n}$-hexane F1, ethyl acetate F2, and n- butanol F3 ) for the 
extraction of the antimicrobial agent from $P$. plebejum, PP, E. hirta, EH, ethyl acetate (F2) was the best solvent for extraction of the antimicrobial substance of 2 medicinal plant. The synergistic effect of fractions of $P$. plebejum , PP\& E. hirta, $\mathrm{EH}$ indicated from table (4) that, mixture of F2 of both extracts was more effective and exhibited the highest antimicrobial activity against MRSA. [19] reported that methods used in extraction of the plant material can influence the chemical composition of the extracts and potentially the biological activity is not new. The more information on the product that is provided in research, the greater will be the ability to compare among studies and understand differences in results that may emerge.

[13] reported that, synergism might play a major role in medicinal plant extracts that were active when the MIC of the mixture was determined, while the separated components showed no antimicrobial activity.

Parameters controlling the growth of MRSA in relation to ethyl acetate extract of E.hirta, EH and P. plebeium, PP
For the purpose of improving the activity of ethyl acetate extract of P.plebeium and $E$ hirta as an antimicrobial agent, different parameters were studied. Results recorded in Table (5) showed that, the best incubation temperature used to storage of ethyl acetate extract of E.hirta, $\mathrm{EH}$ and P. plebeium was $25^{\circ} \mathrm{C}$ against MRSA, B39 It has been noticed that, the incubator time at such temperature play an important role. In the antimicrobial activity of the extract but on time up to it the antimicrobial activity was reduced.

On the other hand, the effect of different $\mathrm{pH}$ 's on the antimicrobial activity of ethyl acetate extract of P.plebeium, PP and E hirta, EH as an antimicrobial agent, against MRSA was tested, the results revealed that, $\mathrm{pH} 5$ was more effective against MRSA, B39 which the mean diameter of inhibition zone was $27 \mathrm{~mm}$ but when the $\mathrm{pH}$ was changed up and down the best $\mathrm{pH}$ value it was less effective. The acidic and alkaline $\mathrm{pH}$ exhibited activation in the antimicrobial activity of P.plebeium, PP and E. hirta, EH against MRSA table (6). No available literature was found concerning this.

Table 2a. Determination of (MIC) of the plant extracts of P. plebeium, PP against MRSA. B39

\begin{tabular}{|c|c|c|c|c|c|c|c|c|c|c|c|c|c|c|c|}
\hline \multirow{3}{*}{$\begin{array}{l}\text { Bacterial } \\
\text { strains }\end{array}$} & \multicolumn{15}{|c|}{$\begin{array}{c}\text { Plant extracts } \\
\text { Mean diameter of inhibition zone of P.plebeium, PP }(\mathrm{mm})\end{array}$} \\
\hline & \multicolumn{3}{|c|}{$100 \mathrm{mg} / \mathrm{m}$} & \multicolumn{3}{|c|}{$50 \mathrm{mg} / \mathrm{m}$} & \multicolumn{3}{|c|}{ I $25 \mathrm{mg} / \mathrm{ml}$} & \multicolumn{5}{|c|}{$12.5 \mathrm{mg} / \mathrm{ml} 6.2 \mathrm{mg} / \mathrm{ml}$} & \\
\hline & 22 & \pm & 1 & 20.67 & \pm & 0.58 & 18.7 & \pm & 0.6 & 0 & \pm & 0 & 0 & \pm & 0 \\
\hline
\end{tabular}

Table 2b. Determination of (MIC) of the plant extracts of $E$. hirta, EH against MRSA B39

\begin{tabular}{|c|c|c|c|c|c|c|c|c|c|c|c|c|c|c|c|}
\hline \multirow{3}{*}{$\begin{array}{l}\text { Bacterial } \\
\text { strains } \\
\text { MRSA,B39 }\end{array}$} & \multicolumn{15}{|c|}{$\begin{array}{l}\text { Plant extracts } \\
\text { Mean diameter of inhibition zone of } E \text {. hirta }, \mathrm{EH}(\mathrm{mm})\end{array}$} \\
\hline & \multicolumn{3}{|c|}{$100 \mathrm{mg} / \mathrm{m}$} & \multicolumn{3}{|c|}{ I $50 \mathrm{mg} / \mathrm{m}$} & \multicolumn{3}{|c|}{ I $25 \mathrm{mg} / \mathrm{ml}$} & \multicolumn{5}{|c|}{$12.5 \mathrm{mg} / \mathrm{ml} \quad 6.2 \mathrm{mg} / \mathrm{ml}$} & \\
\hline & 20.67 & \pm & 0.58 & 19.67 & \pm & 0.58 & 16.7 & \pm & 0.6 & 0 & \pm & 0 & 0 & \pm & 0 \\
\hline
\end{tabular}

Table 3. Effect of different solvents of plant extracts of P. plebeium, PP and E. hirta, EH on the selected pathogenic bacterial strain under study

\begin{tabular}{lcccccccc}
\hline \multirow{2}{*}{$\begin{array}{l}\text { Plant extracts } \\
\text { Strains }\end{array}$} & \multicolumn{3}{c}{ Euphorbia hirta (EH) } & & \multicolumn{3}{c}{ Polygonum plebeium (PP) } \\
\cline { 2 - 3 } \cline { 5 - 7 } MRSA, B39 & F1 & F2 & F3 & & F1 & F2 & F3 \\
\hline
\end{tabular}

F1: Extraction using n-hexan solvents F2: Extraction using ethyl acetate solvents F3: Extraction using n-butanol solvents 


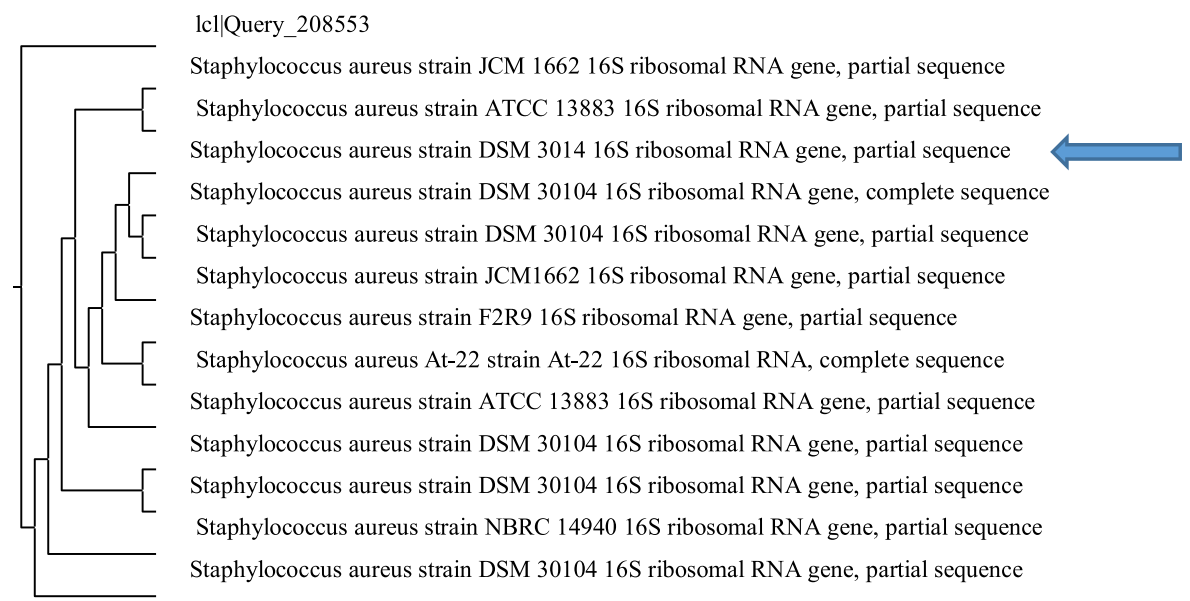

Fig. 1. A dendogram showing the sequence relationships between, Staphylococcus aureus strain DSM 30104 (117686) using 16S ribosomal RNA gene, partial sequence, and several other Staphylococcus aureus strains based on $16 \mathrm{~s} r$ RNA gene sequencing

In addition, the antimicrobial activity of mixture of ethyl acetate of E.hirta, $\mathrm{EH}$ and P.plebeium, PP exhibited slight effectiveness under static condition against MRSA, B39 which the mean diameter of inhibition zone was $28.67 \mathrm{~mm}$ (fig. 2-b).

In the present investigation, different carbon sources in order to determine the best one, monosaccharide xylose was found exhibited the highest antimicrobial activity in combination with mixture of ethyl acetate extracts of P.plebeium ,PP and E hirta, EH for microbial isolate MRSA, B39 They may induce synergetic activity with extract(fig.2-c).

Data represented graphically in fig. (2-d) declared that, not affected by the different types of amino acids for MRSA.

By using different metallic ions with various concentrations $(50,100,200 \mathrm{ppm})$ in combination with ethyl acetate extracts of $P$. plebeium, PP and E. hirta, EH against MRSA fig. (2-e). resulted in inhibition in the antimicrobial

Table 4. Effect of $\mathrm{F} 2$ (P. plebeium, PP and E. hirta, EH) \& F3 (P. plebeium, PP and E. hirta, EH) on MRSA,B39

\begin{tabular}{lcc}
\hline Strains & F2 (EH+PP) & F3 (EH +PP) \\
\hline MRSA, B39 & $31 \pm 0$ & $28 \pm 0$ \\
\hline
\end{tabular}

F2: Extraction using ethyl acetate solvent F3: Extraction using $\mathrm{n}$-butanol solvent activity against MRSA,B39 comparing with control. Thus the addition of any metallic ions must be restricted and avoided.

Data represented graphically in fig.( 2-f) indicated that, different vitamins with various concentrations in combination with ethyl acetate extracts of P. plebeium, PP and E. hirta, EH were studied .resulted in inhibition in the antimicrobial activity against MRSA,B39 comparing with control. Thus the addition of any metallic ions must be restricted and avoided.

Data represented graphically in Fig. (2-g) indicated that, the ethyl acetate extracts of $P$. plebeium, $\mathrm{PP}$ and E. hirta, EH was no effective at any concentrations of multivitamins capsule on MRSA.

Separation and Purification of the Antimicrobial substance from E. hirta, EH, P.plebeium, PP

Column chromatography

Column chromatography for separation of active antimicrobial substance from ethyl acetate extract of P.plebeium, PP

Data illustrated graphically in Fig. $(3,4)$ Indicated that, the maximum activity could be recorded in 2 peaks. Peak I fractions (44-56) inhibited the growth of MRSA, B39 by $(12.6,15.6$, $22,24.6,29.3,31.6,34.3,36,31,25.3,18.6,15$ and $14.3 \mathrm{~mm}$ ) respectively. Peak II fractions (59-65) inhibited the growth of MRSA, B39 by $(18,23.3$, $28,24.6,17.6,15.6$ and $14.3 \mathrm{~mm}$ ) respectively.

In view of the findings of other investigators, [20] found that, the antimicrobial 


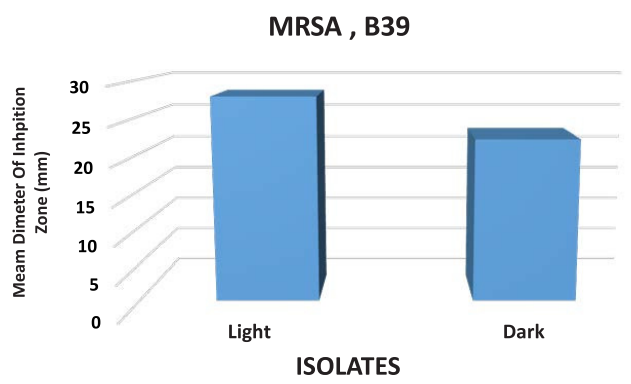

Fig. 2-a. Antimicrobial activity of mixture of ethyl acetate extracts of $P$. plebeium, (PP) and E. hirta ( $E H)$ against MRSA B39 in relation to dark and light.

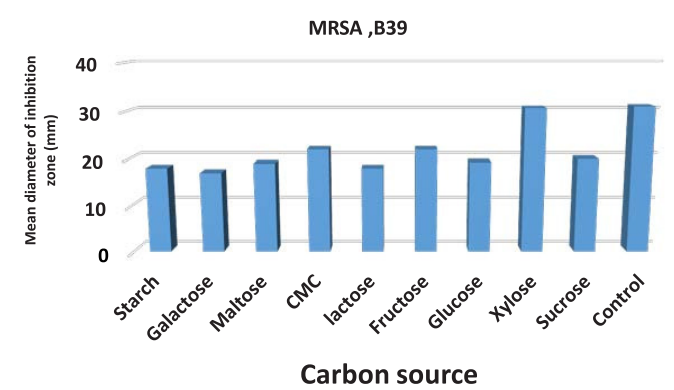

Fig. 2-c. Effect of different carbon sources on the mixture of ethyl acetate extracts of P. plebeium and E.hirta against MRSA B39

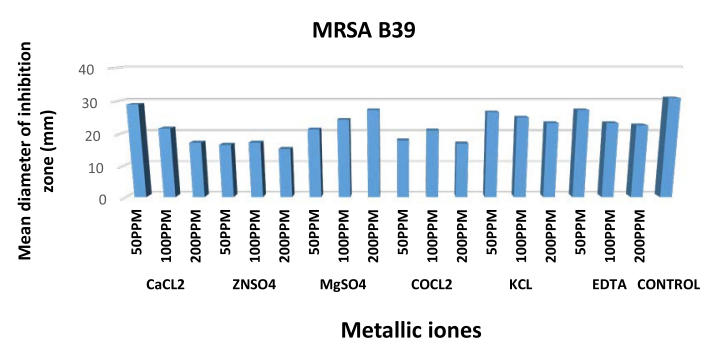

Fig. 2-e. Antimicrobial activity of mixture of ethyl acetate extracts of $P$. plebeium and E.hirta against MRSA B39 in relation to different metallic ions

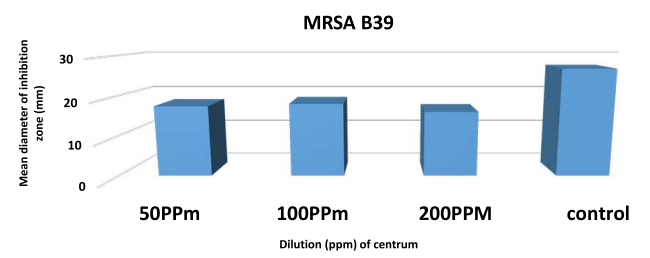

Fig. 2-g. Antimicrobial activity of mixture of ethyl acetate extracts of $P$. plebeium and E.hirta plant extract of P.plebeium, $P P$ and E. hirta, EH against MRSA B39 in relation to multivitamins capsule

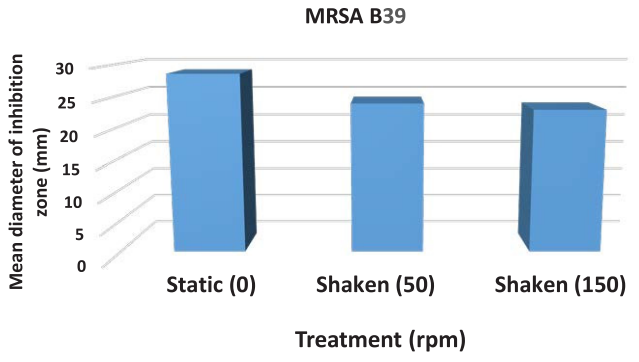

Fig. 2-b. Antimicrobial activity of mixture of ethyl acetate extracts of $P$. plebeium, $(P P)$ and E.hirta, (EH) against MRSA B39 in relation to static and shaken conditions

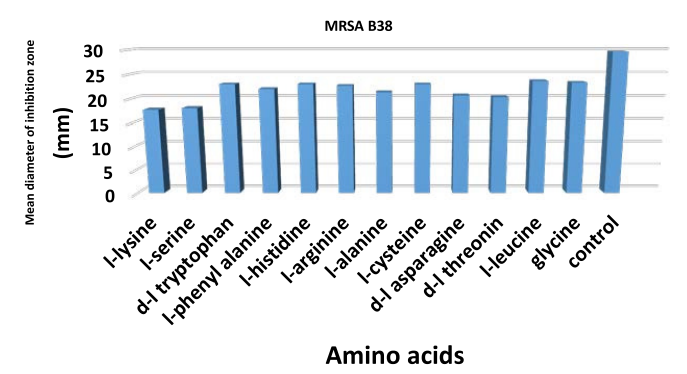

Fig. 2-d. Antimicrobial activity of mixture of ethyl acetate extracts of $P$. plebeium and E.hirta against MRSA B39 in relation to different amino acids

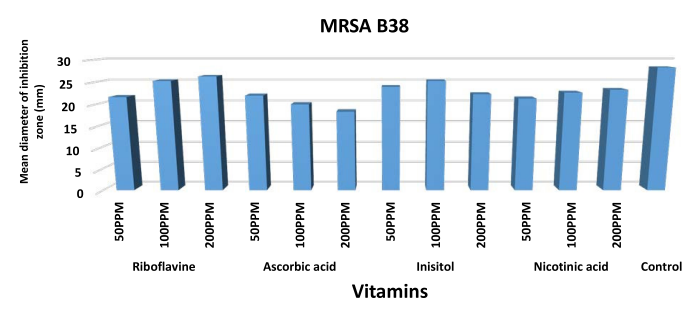

Fig. 2-f. Antimicrobial activity of mixture of ethyl acetate extracts of $P$. plebeium and E.hirta against MRSA B39 in relation to different vitamins

activity was within the third fraction of column chromatography. This fraction was then subjected to gel filtration using Sephadex G-100. Two peaks were obtained. Peak one possessed higher antimicrobial activity. This peak was then subjected to ion exchange Chromatography using DEAE Sephadex. Only peak 4 from six peaks obtained showed as light antimicrobial activity

[21] showed that, the chloroform extracts exhibited the least antimicrobial activity 


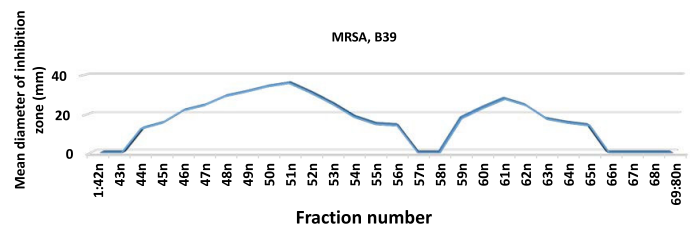

Fig. 3. Fractionation pattern of active antimicrobial substances from P. plebeium (PP) extract and their effect against MRSA, B39

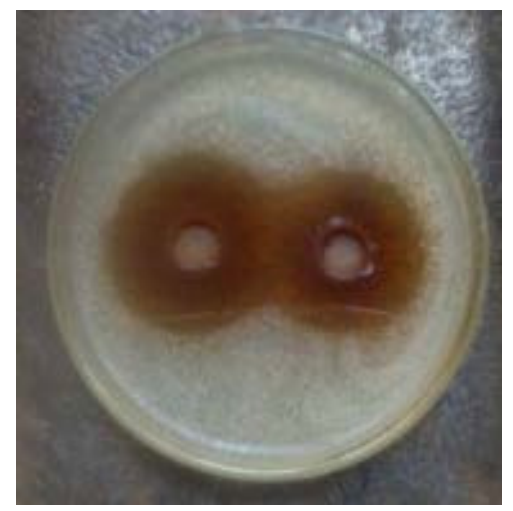

The clear zone on the left reffered to Peak I, and on the right reffered to Peak II

Fig. 4. Fractionation pattern of active antimicrobial substance from P.plebeium (PP) extract and their effect against MRSA, B39

as compared to other solvent extracts from different medicinal plants. The reasons could be a low concentration of antimicrobial compounds in these extracts.

Column chromatography for separation of active antimicrobial substance from ethyl acetate extract of $E$. hirta, EH

Data represented graphically in fig. (5, $6)$ Indicated that, the maximum activity could be recorded in 2 peaks.

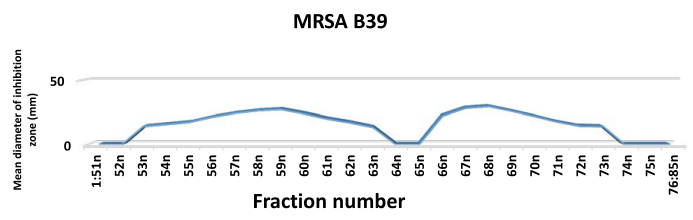

Fig. 5. Fractionation pattern of active antimicrobial substances from $E$. hirta $(E H)$ extract and their effect against MRSA, B39
In addition, Peak I fractions (53-63) inhibited the growth of MRSA, B39 by $(14.3,16$, 17.6, 21.6, 24.6, 26.6, 27.6, 24.3, 20.3, 17.3 and $13.6 \mathrm{~mm}$ ) respectively. Peak II fractions(66-73) inhibited the growth of MRSA, B39 by $(22.6,28.6$, $30,26.3,22.3,18,14.6$ and $14.3 \mathrm{~mm}$ ) respectively.

Peak II of (EH) exhibited the highest antimicrobial activity in case of MRSA.

In view of the findings of other workers, column chromatography packed with silica gel and an eluting solvents composed of various ratios of solvent system was used to fractionation of the crude extract into active fractions [22],[23],[24],[25],[26],[27] and [28].

In atrial to elucidate the synergistic effect of a mixture of all active peaks, the active fractions in each peak were mixed together in glass vials, and then were used for the antimicrobial activity test against MRSA. Data in fig. $(7,8)$ showed that, The mixture of peak I of P. plebeium, PP and peak II of $E$. hirta ,EH was the most effective against MRSA, B39 by ( $39 \mathrm{~mm}$ ) respectively.

Characterization of the active compounds as antimicrobial agents from $P$. plebebium.

The most active fractions on the 6 strains under study were collected (48-49-50-51-59-6061-62). The purified fractions were checked by chromatographic separation on silica gel TLC plate that showed two bands under short wave length. Also, the purity of this compound was confirmed by the total ion chromatogram resulted from mass spectroscopic (MS) analysis of 2 substance.

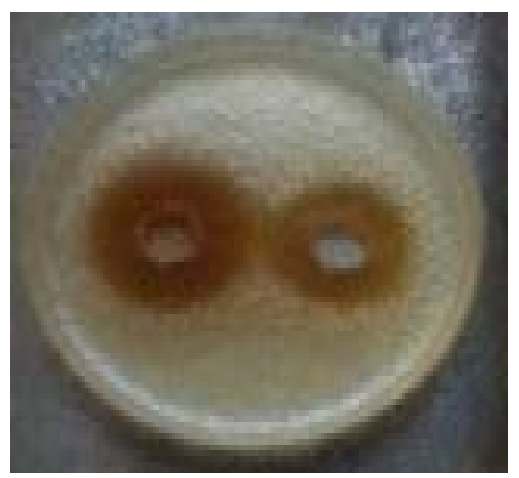

The clear zone on the left reffered to Peak I, and on the right reffered to Peak II

Fig. 6. Fractionation pattern of active antimicrobial substance from E. hirta $(E H)$ extract and their effect against MRSA, B39 


\section{Characterization of the active compound (A) from P. plebjeum}

The purity of the compound was confirmed by chromatographic methods which give one spot on TLC using different mobile phases using different spraying reagents as shown in figure (9). Ultra violet (UV) spectrum of this compound $\lambda \max (\mathrm{MeOH}) \mathrm{nm}$ : 291. Infra red (IR) spectrum $\lambda \max (\mathrm{KBr}) \mathrm{cm}^{-1}: 3420(\mathrm{OH}), 3110-2510(\mathrm{OH}), 1620$, $1600,1518(C=C)$. From the mass spectrum of this compound showed molecular ion peak at $\mathrm{m} / \mathrm{z} 81$ (30\%), 55.5 (20\%), 39 (18.2), $27(15.2 \%)$ and the base peak at $\mathrm{m} / \mathrm{z} 110(100 \%)$ indicated that this compound was identified as hydroquinone with molecular formula $\mathrm{C}_{6} \mathrm{H}_{6} \mathrm{O}_{2}$

[29] reported that, Purified hydroquinone showed promising activity against $P$. aeruginosa MTCC 741, S. aureus MTCC 740 and $K$. pneumoniae. Electron microscopy revealed that, hydroquinone caused damage to bacterial pathogens. This damaged in bacterial cells was caused by the antimicrobial peptides gramicidin $\mathrm{S}$ caused formation of blebs on membrane lead

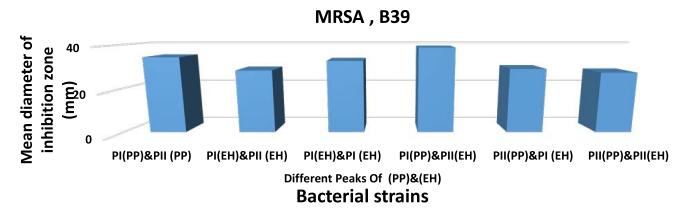

Fig. 7. The antimicrobial activity of a mixture of peak I and peak II for both extracts P. plebeium (PP)\& E. hirta (EH) against MRSA B39

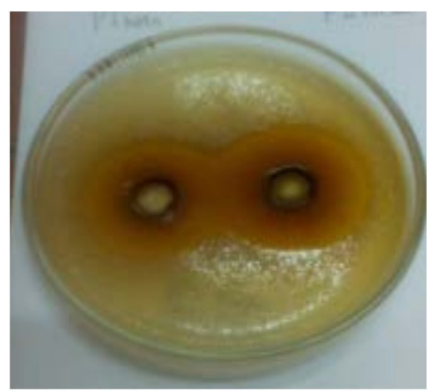

The clear zone on the left reffered to Peak I (PP) \&PII (PP), and on the right reffered to Peak I (PP) \&PII (EH)

Fig. 8. The antimicrobial activity of a mixture of peak I and peak II for both extracts $P$. plebeium (PP) and $E$. hirta, (EH) against MRSA, B39

Table 5. Antimicrobial activity of the mixture of ethyl acetate extract of P.plebeium, PP and E hirta, EH against MRSA, B39 in relation to different incubation temperatures

\begin{tabular}{lcccccc}
\hline \multirow{2}{*}{$\begin{array}{l}\text { Time } \\
\text { (hr) }\end{array}$} & \multicolumn{5}{c}{$\begin{array}{c}\text { Mean diameter of inhibition zone }(\mathrm{mm}) \\
\text { Temperature }{ }^{\circ} \mathrm{C}\end{array}$} \\
\cline { 2 - 7 } & 10 & 25 & 35 & 45 & 100 & 121 Autoclave \\
\hline Zero & $25 \pm 0$ & $29.67 \pm 0.58$ & $27 \pm 0$ & $17.333 \pm 0.58$ & $18 \pm 0$ & \\
$10 \min$ & $22.67 \pm 1.155$ & $28.33 \pm 0.58$ & $24.33 \pm 0.58$ & $18.333 \pm 0.58$ & $19.67 \pm 0.58$ & $18.67 \pm 0.58$ \\
1 & $20.33 \pm 0.577$ & $25.67 \pm 0.58$ & $25.33 \pm 0.58$ & $20.667 \pm 0.58$ & $21.67 \pm 0.58$ & \\
6 & $19.67 \pm 0.577$ & $24 \pm 0$ & $24.33 \pm 0.58$ & $24.333 \pm 0.58$ & $20 \pm 0$ & \\
$2 h$ & $19 \pm 0$ & $22 \pm 0$ & $21.33 \pm$ & $1.1523 \pm 0$ & $19.67 \pm 0.58$ & \\
$4 h$ & $18.67 \pm 0.577$ & $21.33 \pm 1.15$ & $20.33 \pm 0.58$ & $19.333 \pm 0.58$ & - \pm- & \\
& & & & & & \\
\hline
\end{tabular}

Table 6. Antimicrobial activity of the mixture of ethyl acetate extract of P.plebeium, PP and E hirta, EH against MRSA, B39 in relation to different $\mathrm{pH}$ 's

\begin{tabular}{lcccccc}
\hline Time & \multicolumn{7}{c}{ Mean diameter of inhibition zone of $(\mathrm{mm})$} \\
$\mathrm{pH}$ 's & \\
\cline { 2 - 7 } & 2 & 3 & 5 & 7 & 8 & 9 \\
\hline Zero & $20.33 \pm 0.58$ & $21 \pm 1$ & $23 \pm 0$ & $25 \pm 0$ & $18.33 \pm 1.528$ & $17 \pm 1$ \\
10min & $22 \pm 0$ & $23.67 \pm 0.58$ & $24.33 \pm 0.58$ & $26.33 \pm 0.58$ & $18 \pm 1$ & $17.33 \pm 1.15$ \\
1h & $22.33 \pm 1.15$ & $24 \pm 0$ & $27 \pm 1$ & $26 \pm 0$ & $19 \pm 1$ & $17.67 \pm 1.53$ \\
6h & $21 \pm 0$ & $20.33 \pm 0.58$ & $23 \pm 0$ & $25.33 \pm 1.15$ & $18.67 \pm 0.577$ & $17 \pm 0$ \\
24h & $19.33 \pm 0.58$ & $21 \pm 1$ & $22 \pm 1$ & $25.67 \pm 0.58$ & $18.33 \pm 0.577$ & $16.67 \pm 0.58$ \\
48h & $19 \pm 0$ & $19.67 \pm 0.58$ & $20.33 \pm 0.58$ & $25.67 \pm 0.58$ & $18 \pm 0$ & $15.67 \pm 0.58$ \\
\hline
\end{tabular}




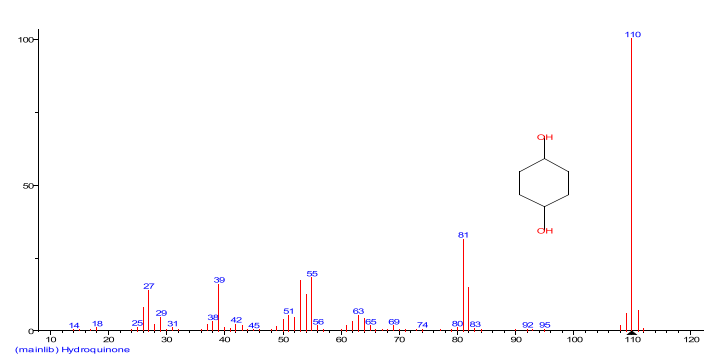

Fig. 9. The mass spectroscopy of compound (A) from P.Plebium

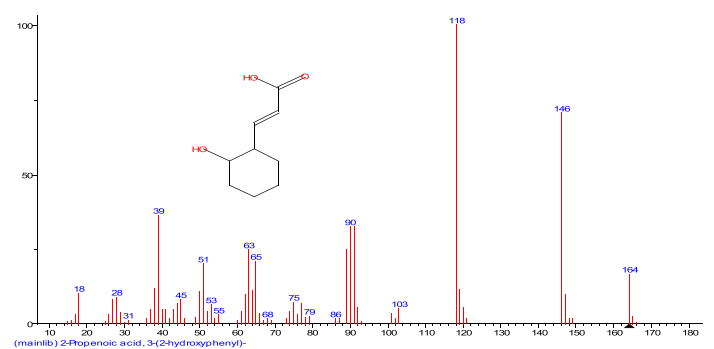

Fig. 10. The mass spectroscopy of compound (B) from P. Plebjum

to membrane lysis and cytoplasmic contents were released out the cell.3.7.2. Characterization of the active compound (B) from P.plebjeum

Characterization of the active compound (B) from P.plebjeum

Compound B isolated as white crystals give one spot on TLC using different systems as it is obvious in figure (10). Ultra violet (UV) spectrum of this compound $\mathrm{B}>\max (\mathrm{MeOH}) \mathrm{nm}$ : 310. Infra red (IR) spectrum $\lambda \max (\mathrm{KBr}) \mathrm{cm}-1: 3420(\mathrm{OH})$, 3100-2500 (OH), 1675 (CO), 1620, 1600, 1515 $(\mathrm{C}=\mathrm{C})$. From mass spectrum showed molecular ion peak at m/z 164 (10\%), 146(75\%), 103 (10\%), 90 (30\%), 65 (20\%), 51 (19\%), 39 (30\%), 18(14\%) and the base peak at m/z 118 (100\%).indicated that this compound was identified as O-coumaric acid (2 hydroxy cinnamic acid with molecular formula $\mathrm{C}_{6} \mathrm{H}_{6} \mathrm{O}_{2}$. The identification of this compound was confirmed with stander ( Tlc, colour reaction, $\mathrm{mp}, \mathrm{mmp}$ ) and by direct comparison data in previous literature, The molecular formula for the compound is $\mathrm{C}_{9} \mathrm{H}_{8} \mathrm{O}_{3}$ and the chemical name is O-coumaric acid ( 2 hydroxy cinnamic acid)

Coumarins are a group of aromatic benzopyrones consisting of fused benzene and alpha pyrone rings. There are 3 isomers of coumaric acids: o-coumaric acid, $\mathrm{m}$ - coumaric acid and $\mathrm{p}$ - coumaric acid that differ by the position of hydroxy substitution of phenyl group. The mechanism of action of gallic acid and coumaric acid was assessed on E. coli, P. aeruginosa and S. aureus. These compounds led to irreversible change in membrane properties (change-intra and extracellular permeability and physicochemical properties) through hydrophobicity changes, decrease of negative surface charge and occurrence of local rupture or pore formation in the cell membranes with consequent leakage of essential intracellular constituents. The overall study emphasizes the potential of medicinal plants derived as antibacterial agents [30].

Funding

This work was not funded by any organization

\section{CONFLIT OF INTEREST}

All the authors declare that they have no conflict of interest.

This article does not contain any studies with human participants or animals performed by any of the authors.

\section{REFERENCES}

1. Byarugaba, D. K., A view on antimicrobial resistance in developing countries and responsible risk factors, International Journal of Antimicrobial Agents, 2004; Vol. 24, no. 2, p: 105-110.

2. Levy, S. The Antibiotic Paradox: How Misuse of Antibiotics Destroys their Curative Powers (Perseus Cambridge, 2002).

3. Ash, C. (ed.) Trends in Microbiology vol.2, 341-422 (Elsevier, Cambridge, UK, 1994).

4. Barber, M. Infection by penicillin resistant Staphylococci. Lancet 2, 641-644 (1948).

5. Watanabe, T. Infective heredity of multidrug resistance in bacteria. Bacteriol. Rev. 27, 87-115 (1963).

6. Levy, S.B. Antibiotic resistance: consequences of inaction. Clin. Infect. Dis. 33 Suppl. 3, S124-S129 (2001).

7. Elwell, L., Roberts, M., Mayer, L. \& Falkow, S. Plasmid-mediated â-lactamase production in Neisseria gonorrhoeae. Antimicrob. Agents Chemother. 11, 528-533 (1977).

8. De Graaff, J., Elwell, L.P. \& Falkow, S. Molecular nature of two â-lactamase-specifying plasmids isolated from Haemophilus influenzae type b. J. Bacteriol. 126,439-446 (1976).

9. Okeke, I. N., Laxminarayan, R., Bhutta, Z. A., Duse, 
A. G. D., Jenkins, P., O'Brien, T. F., Pablos-Mendez, A. and Klugman, K. P., 2005, Antimicrobial resistance in developing countries. Part I: recent trends and current status, The Lancet Infectious Diseases, Vol. 5, p: 481-493

10. Simões, M., Bennett, R. N. and Rosa, E. A. S., Understanding antimicrobial activities of phytochemicals against multidrug resistant bacteria and biofilms, Natural Product Reports, 2009, Vol. 26, p: 746-757.

11. Duke, S. O. Plant terpenoids as pesticides. In toxicology of plant and fungal compounds. Handbook of Natural Toxins, 1991, Vol. 6., R.F. Keeler and A.T. Tu, (Eds.). Marcel Dekker, New York. pp. 269-296.

12. Praveen, D. \& Sharmishtha, P.(2012). Phytochemical Screening and Antimicrobial activity of some medicinal plants against Multidrug resistant bacteria from clinical isolates; India.J.Pharm.Sci.74(5):443-450.

13. Schardl CL, Grossman RB, Nagabhyru P, Faulkner JR, Mallik UP (2007). "Loline alkaloids: currencies of mutualism". Phytochemistry 68 (7): 980996. doi:10.1016/j.phytochem.2007.01.010. PMID 17346759.

14. Janakat,S.,Al-Fakhiri, S.and Sallal, A.k. Evaluation of antibacterial activity of aqueous and methanolic extracts of the truffle Terfezia claveryi against P.aeruginosa. Saudi Med. J. 2005; 26, pp.952-955.

15. Balbaa, S.I.; Hilal, S.H.and Zaki, A.Y. Medicinal plant constituents, $3^{\text {rd }}$ edition 1981. General Agency for University and School Books

16. Amita $S$, Chowdhoury R, Thungaathia $M$, Romamuthy T, Nair GB,Ghosh A., 2003, Class A Integrons and SXT Elements in El Tor

17. Handa, S. S.; Khanuja, S. P. S.; Longo, G.; Rakesh, D. D. Extraction Technologies for Medicinal and Aromatic Plants. United Nations Industrial Development Organization and the International Center for Science and High Technology, Trieste, 2008, p.7

18. El-Mahmood, A.M.(2009), Antimicrobial activity of crude extracts of Euphorbia hirta against some bacteria associated with enteric infections. J. Med.Plants Res. 3, 498-505.

19. Cooper, R. and Kronenberg, F. Botanical Medicine:from bench to bedside. Mary Ann Liebert, Inc. USA., 2009

20. Janakat,S.; Al-Fakhiri,S. and Sallal, A.K. A promising peptide antibiotic from Terfezia claveryi aqueous extract against staphylococcus aureus in vitro. Phototherapy Research. 2004; 18(10),pp.810-813.

21. Rios, J. L, Recio, M.C. Medicinal plants and antimicrobial activity. J Ethnopharmacol; 2005; 100:80-4.

22. Kumigiri, K.; Suzuki, Y.; Shibazaki, M.; Morioka, M. and Suzuki, K. I. Kalimantacius A, B and $C$, novel antibiotics from Alcaligenes sp. Y102632s. I-Taxonomy, fermentation, isolation and biological properties. J. Antibiot., 1996; 49 2): pp. 136-139.

23. Tabata, Y.; Miike, N.; Hatsu, M.; Kurata, Y.; Yaguchi, T.; Someya, A.; et al. PF1092 A, B and C, New nonsteroidal progesterone receptor ligands produced by Penicillum oblatum. Taxonomy of producing strain, fermentation, isolation and biological activities. J. antibiot., 1997; 50(4): pp. 304-313.

24. Imnagaki, T.; Kaneda, K.; suzuki, Y.; Hirai, H.; Nomura, E.; Sakakibara, T.; et al. CJ-12, 373, a novel topoisomerase II inhibitor: Fermentation, isolation, structure, elucidation and biological activities. J. Antibiot., 1998; 51(2): pp. 112116.

25. Momose, I.; Sekizawa, R.; Hashizume, H.; Kinoshita, N.; Homma, Y ;.Hamada, Y,; et al. Typropeptins $A$ and $B$, new proteasome inhibitors produced by Kitasatospora sp. MK 993-dF2. Taxonomy, isolation, Physicochemicalproperties and biological activities. J Antibiot., 2001; 54(12 ): pp. 997-1003.

26. El-Henawy, S. B. Recycling of solid wastes using a safe microbiological system. M.Sc. Thesis, Microbiology Dept, Fac. of Science, Al-Azhar Univ. Cairo. Egypt, 2006.

27. El-Tantawy, N. I. The bioprocess development for the production of bioactive material (s) by actinomycetes. M.Sc. Thesis, Botany Dept, Fac. of Science, Zagazig Univ, Cairo, Egypt, 2008

28. Khalifa, M. A.; Haroun, B. M.; Atta, H. M.; Abul- Hamd, A. T. and El-Enshasy, H. (2008). Vernamycin-a biosynthesis by streptomyces sp-az-sh- 29: characterization, fermentation, purification and biological activities. Botany and Microbiology Dept. Faculty of science (Boys), Al-Azhar University, Cairo, Egypt, 2008.

29. Venkadapathi, J.; Periasamy, A.; Maria, V. and Palaniyandi, $\mathrm{V}$. Isolation of hydroquinone metabolite from halotolerant B. methylotrophicus $\mathrm{MHC} 10$ and its inhibitory activity towards bacterial pathogenes. J. Bioprocess and Biosystem Engineering. 2016; 39(3):429-439.

30. Borges, A.; Ferreira, C.; Saavedra, M. J. and Simoes, M. Antibacterial activity and mode of action of gallic acid against pathogenic bacteria.J. Microb Drug Resist. 2013; 19(4):256-65. 